\title{
Using Imagination as an Epistemic Tool
}

\author{
Kristina Veinbender \\ Univerzita Karlova, CZ
}

\begin{abstract}
VEINBENDER, K.: Using Imagination as an Epistemic Tool Philosophica Critica, vol. 6, 2020, no. 2, ISSN 1339-8970, pp. 30-42.

The research question of the paper is whether we can acquire knowledge by using our imagination. I work with later Wittgenstein's thesis according to which there is a difference between ordinary and philosophical doubt, I call them local and global doubts. According to Wittgenstein, philosophical doubt is not rooted in any language game, since it doubts something undoubtable. In a similar way, I distinguish local and global imagining suggesting only the local one can bring a piece of knowledge. In the last part of the paper I search for scientific evidence for my thesis and conclude that only particular examples help us to learn or predict our future experience.
\end{abstract}

Keywords: Imagination - Scepticism - Wittgenstein - Philosophical doubts - Epistemology of imagination

To know, Ludwig Wittgenstein says, means "to perceive an outer event through visual rays which project it as it is into the eye and the consciousness" (Wittgenstein 1969, 90). In contrast, certainty and doubt "show how our imagination presents knowledge, but not what lies in the bottom of this presentation" (Wittgenstein 1969, 90). Roughly speaking, according to Wittgenstein imagination organizes our knowledge, but it is not knowledge itself. Can we nevertheless use imagination to acquire knowledge or simply to learn? This is the main concern of this text.

In the first part of this paper I would like to argue that imagination underlies our ability of having a doubt and being certain, since it provides us with an ability to think of alternatives within a present language game as well as to make up an imaginative alternative game with new doubts and certainties. In the first part I will suggest that only a local type imagining within the existing or present form of life and language game seems to be a proper epistemic tool for enquiring knowledge.

In the second part I will show that my previous hypothesis was wrong and that local imagination is not always a reliable source of knowledge. 
But in several cases it can bring us more or less exact estimation of outcomes and can be helpful. This suggestion will be supported by few cognitive studies of imagination.

\subsection{Grounds for Imagining}

If we imagine facts otherwise as they are, certain language-games lose some of their importance while other become important (Wittgenstein $1969,63)$. That implies that certain doubts lose their intelligibility while others become appropriate. Indeed, let's imagine a world where dogs normally fly instead of walking. Seeing a dog walking, we can doubt its ability to fly by assuming e.g. dog's wing is broken. In our everyday world, doubting dog's ability to fly is senseless. Therefore imagination can change the direction of our iquiry by changing objects of doubting.

People can use their ability to imagine a situation different from the actual one whenever they want to, even under the condition of "lacking of doubts" (Wittgesntein 1969, 4). There are no doubts I have a brain, but I can imagine the situation of being a zombie with an empty skull. It seems that we can imagine (or at least we can say we can imagine) a lot of possible alternative scenarios, although there is no reason to doubt the situation as it is. But is imagining alternatives to undoubtable statements rooted in the same form of life and the same language game?

There is no doubt that the force of gravitation is present in my room since all things around me are lying still in their place instead of floating around, which I can fully imagine in case I'm an astronaut on a space station. Is imagining that situation equal to having a doubt about gravitation in my room? The answer is no, since imagining otherwise means making up a new form of life or a new language game absolutely different from the actual one. Imagination just presupposes identifying grounds for doubting in doubtable situations, but it is not an act of doubt itself.

Let's reverse the causality. Does doubting presuppose imagining of alternative facts? I suppose yes. If a book started floating in the middle of a room, I would probably doubt the gravity intensity by imagining an alternative explanation which fits best the existing situation. Doubting and imagining seem to be two almost simultaneous processes here. Nevertheless, I will probably maintain certain fundamental beliefs like my adequate ability of perception. Imagination seems to be a key tool to identify grounds for doubting while maintaining certainties.

The feature which seems to be essential for doubt, according to Wittgenstein, is having reasons for doubting, as it follows from the following quote: „But what about such a proposition as „I know I have a brain“? 
Can I doubt it? Grounds for doubt are lacking!” (Wittgenstein 1969, 4). When grounds are missing, it seems neither rational, nor intelligible to doubt something. On contrary to have no doubt according to Wittgenstein implies a situation when "the expression of doubt would be unintelligible" (Wittgenstein 1969, 10). Someone who doubts whether the Earth has been existing for at least 100 years, might have a scientific doubt. That means imagining a falsifying situation and looking for a proof which undermines actual scientific evaluation of the age of the Earth. In contrast, philosophical doubting is completely different in its nature and its implication method (Wittgenstein 1969, 259).

In his article "Defending common sense" Malcolm distinguishes two kinds of doubts: an ordinary one and a philosophical (or rather "sceptical" one). By exploring a number of ordinary language examples, he demonstrates that a philosophical doubt cannot be a particular example of a doubt in ordinary sense. According to him, philosophical doubting occurs only in case there are no grounds or reasons for doubt and there is not a question whether so and so is true (Malcolm 1949, 204). Malcolm gives as an example of doubting, a situation when we doubt whether something is tree and suggests that philosophical doubting takes place if only we see a tree clearly enough and there is no doubt if it is a tree in an ordinary sense. Absence of reasons for doubting in case of a philosophical doubt means there is no "investigation" which would provide a proof to stop doubting. There is no mode of inquiry, which is appropriate to conduct, in order to become certain on regard of a particular philosophical issue. In addition, since there are no grounds for doubts, there are neither grounds for an alternative situation or fact within the game.

"I doubt there is a high wall" implies a certain procedure which would provide the proof of its existence following the statement. It can be uttered by a burglar who is trying to get to someone's garden unseen. Finally after discovering the wall, he would say: "Too bad. There could have been just a fence like in the other neighbors' gardens." Expecting a fence on the place of a wall is imagining an alternative within the game. That is not a situation when a philosopher has a chance to doubt. Only in case of seeing a high wall clearly in front of you with a possibility to touch it or to lean back on it, it is a good chance to conduct philosophical doubting. Doubting existence of a wall, its height or length in this case implies doubting our ability to perceive generally. The only imaginable alternative here is non-existence of the world or serious malfunctions of our perception, in fact, which is quite unimaginable.

According to Duncan Pritchard, in his late notes Wittgenstein is trying to show us that the "puzzle that is arising out of entirely natural epistemic 
moves, in fact trades on philosophical picture that is very different from our normal epistemic practices" (Pritchard 2015, 67). In my opinion imagining alternatives within the game is one of these normal epistemic practices. Using imagination to imagine a different form of life creates a paradox mentioned in the beginning - our imagination rooted in our form of life and our lanaguge. When speaking or writing of made-up worlds we still do it in our language and project our form of life in the very piece of thought imagined by your mind. As Austin suggests, if something unimaginable, completely out-of-our-form-of-life would occur, we wouldn't be able to describe it with our ordinary words: „Suppose that I live in harmony and friendship for four years with a cat: and then it delivers a philippic. We ask ourselves, perhaps, ,Is it a real cat? or is it not a real cat?' ,Either it is, or it is not, but we cannot be sure which.' Now actually, that is not so: neither ,It is a real cat' nor ,it is not a real cat' fits the facts semantically: each is designed for other situations than this one: you could not say the former of something which delivers philippics, nor yet the latter of something which has behaved as this has for four years... The difficulty is just that: there is no short description which is not misleading: the only thing to do, and that can easily be done, is to set out the description of the facts at length. Ordinary language breaks down in extraordinary cases"(Austin 1979, 36).

Following Austin my first argument is that we cannot actually imagine other forms of life in an effective way, since we use language rooted in our form of life. In the next chapter I will discuss the problem from the perspective of commitment to local language games.

\subsection{Local and Global}

In this section I would like to show that imagination seems to be useful only when it is commited to a local language game. On contrary, global imagining creates a paradox.

"When things are clear, there is no need to say them," this is a probable reaction of Moore's observer on his utterance "I know this is a tree" while both of them are watching the tree closely (Malcolm 1949, 215). Unlike Tractatus, where Wittgenstein states that only clear things should be uttered, this seems to be the opposite case. Pritchard distinguishes two kinds of rational evaluation: a localized one, which occurs in everyday epistemic context and a globalized one, which is employed by sceptics. According to Wittgenstein (and Pritchard), all rational doubts are essentially "local", meaning they take place relative to fundamental, so called (by 
Wittgenstein) "hinge" commitments, which are immune to rational evaluation (Wittgenstein 1969, 341-343).

Pritchard calls this approach an "undercutting" treatment of the sceptic problem (Pritchard 2016, 67). By that he means that local evaluations preclude the possibility of global ones. For instance, we can't think of whether to get the chair repaired or not if we doubt the chair's existence. In other words a local doubt can be only conducted if a global one is absent. An example of local evaluation in an everyday situation and a global one doubting world's existence or perception ability seem to be just two polarized cases. However, is "global" doubting a possible case at all?

It seems that imagination, similarly to doubt, is profoundly "local" since it is relative to the framework of a language game. Try to imagine a local situation where doubts could occur. It seems to be simple. Now try to imagine a "global" situation when one doubts the existence of the external world or even doubts his or her ability to doubt? It seems that doubting globally is not relative to any situation and it makes no difference what particular situation is being imagined. Neither imagination, nor doubting make sense in a "global" way.

"Automatic" existential claim is obvious in our everyday life. Children do not learn that things exist, they learn how to handle those undoubtedly existing things instead. When a child learns language, it learns at the same time what is to be investigated and what is not, Wittgenstein concludes (Wittgenstein 1969, 476). Indeed you can hardly find a child playing a game in which chairs do not exist. Nevertheless almost every child game is based on alternating a thing's function, for instance imagining that chairs are a train. In other words, imagining means investigating possibilities within the game, not building up a new game. What makes local context of language games so powerful? According to Wittgenstein, certainty is a part of logic and game description. That is why doubting makes sense only when certainty is a ground of a game. Doubt itself rests only on what is beyond doubt (Wittgenstein 1969, 519).

Indeed, couldn't we live without being certain of at least something? Imagine a situation: you are an orphan who is introduced to his mother after many years and when you look at her, you say: "I doubt this is my mother". "How do you know?", a possible reaction would follow. Your doubting an identity of your mother can only take place if you know something about her that doesn't fit the woman you are introduced to. It is also plausible you rely on genetics when you see your possible mother's appearance which is absolutely different from yours. In this case you are certain of the inheritance principle. But in a situation when you know nothing of your mother and the mother-to-be seems very similar to you, is it 
intelligible to doubt or even not to doubt this statement? Doubting implies imagining possibilities, but it must be grounded in certainty which cannot be reimagined without resetting the whole game including power of my imagination.

As G. Ryle notes "we never speak of a person believing how" (Ryle $1965,28)$, but believing that. In the same manner, we can say that we can imagine that nothing exists, although there is no epistemological application for that kind of "image". Imagination in this case doesn't provide us with any tools to explore. In a similar way, although imagining a bat works for us well, imagining you are bat brings you nothing except for acknowledging that you don't know "what is like to be a bat". According to Nagel's famous paper (1974), imagining a bat and imagining what is like to be a bat are two different kinds of cognitive processes. Confusion between sympathetic imagination (putting myself in a conscious state resembling the thing itself) and perceptual imagination (putting myself in a conscious state resembling the state I would be in if I perceived it) is a confusion based on attitudes. The main source of confusion according to him is hidden in our inability to combine both attitudes at the same time. I can imagine both irresistible force and immoveable objects, Sorensen puts as an example of the double attitude, but can I imagine both (Sorensen 2016, 434)? Similarly there is a paradox emerging when we imagine a world without a single mind and therefore imagination. Even in an imagined world where all things are floeating our imagination might be different frome the one we operate with now.

In his paper "Thought experiment and imagination" Roy Sorensen claims that "imaginable" has the same logical generality as "interesting". Indeed, everything can be interesting: dogs, cars, numbers, ideas, experience. Since what is interesting must be imaginable, he goes on, imaginable must be as capacious as "interesting" (Sorensen 2016, 435). Our question is whether all claims of "being able to imagine" must be treated in the same way.

\section{Imagining and Belief: What's the Difference?}

The previous section showed how imagination and belief bear certain similarities. Although imagining shares certain common features with mental acts and non-attitudinal mental states, it does not fit strictly any of those categories. That is why it has to be characterized in Kind's opinion in terms of three features: directedness, activity and phenomenology (Kind 2001, 89). Imagining an object is directed mental state in a sense it is concerned with an object of imagining, either real or imagined one. For 
example, my imagination can be directed to both Donald Duck and Donald Trump to the same extent, although one of them is not real. According to Kind, imagining could be also regarded as an active mental act, though it is not constantly intentional one. In other words when we imagine we do something in contrast with being in pain, with having a belief, perceiving or hallucinating. However, the distinction between active and passive states is not, as Kind admits, wholly uncontroversial.

Kind also claims imagining be a phenomenological mental state, again in comparison with a state of having beliefs. She suggests considering an example of her friend wearing an orange dress. Imagining this has, according to her, clearly phenomenological character. Moreover, she adds, the qualitative feel involved is essential to it. In her opinion every imagining involves an experiential aspect and image is a necessary part of it. Although both activity and phenomenology as main characteristics of imagination could be disputed, I am more interested in distinguishing here the status of imagination and belief.

Comparing imagination and belief could lead to the conclusion that there are a number of common features but also intrinsic properties which seem to be different in both cases. According to Eric Schwitzgebel (2000) there are at least three features of belief that imagination lacks. First of all, beliefs create and eliminate certain beliefs. If you believe that $p$, you cannot believe that not-p. On the other hand, imagining $p$ doesn't exclude the possibility of imagining not-p. I can imagine I am Cinderella and I can imagine I am not. Secondly, having any belief presupposes having a meta-belief according to which we perceive things in a right way. Believing that insect bite hurts presupposes believing I can perceive the pain in a right moment. On contrary, imagination is not necessarily connected to our perception. For example, reading novels and imagining its characters is not based on perception of a book's pages. Third, our actions are often motivated by our beliefs. On the other hand, we rarely act on basis of our imagination.

In an opposite way, there are also properties of imagination that belief lacks (Sinhababu 2016, 112). In contrast with belief it is easy to perform an intentional action of imagining. I want to imagine lying in a bed, I can do it on purpose, but I cannot believe on purpose that I am lying in a bed when standing. Of course intentionality is not always the case. Sometimes reading Stephen King's book or a horror movie can trigger imagining horror scenes without wishing to do so and sometimes even make us not being able to stop it.

Finally, a property which seems to distinguish believing and imagining is a strong phenomenological feature of imagining. A number of 
experiments seem to show an explicit similarity between imagining (at least non-propositional imagining) and perceiving. For example research by O'Craven and Kanwisher (2000) demonstrates that imagining faces and places activates very similar regions of the brain to those involved in actual seeing faces and places (Sinhababu 2016, 114).

In his paper "Imagination and belief" Neil Sinhababu mentions few theories which explore the status of imagination either being inherently different from belief, or supporting possible existence of intermediate states between the two mental states (Sinhababu 2016). Shaun Nichols and Stephen Stich (2000) argue that the compatibility of imagining that $p$ and believing that non-p proves that beliefs and imaginative representations are of different types ("Pretense box"). I believe I'm not a president, but I can imagine I am. Those two propositions are not in a conflict since according to Nichols and Stich they belong to different mental "boxes". According to this reasoning philosophical experiment should be squatted in a "pretense box", that's why different game rules are applied to beliefs and imagination representations. In Nichol's and Stich's opinion the main difference could be explained by how desire and imagination can interact to cause emotions. That is a possible explanation for the reason why excercising a thought experiment where brain has been put out of a body does not overwhelm us with a horror. We concentrate on dealing with a topic of a thought experiment in ways that "don't involve imaginative engagement with horrific features of the situations" (Sinhababu 2016, 116). "Assume" and "suppose" are the words which emphasize the non-affective nature of our imaginative projects. Emotional engagement control and ability to focus seem to be the tools which distinguish imagining from believing. But what about imagination representation which does not involve emotions like "the tree is two meters high"? Is there any difference between imagining and believing it is true?

Although it belongs to the opposite opinion camp in its rejecting "different boxes" explanation, the norm-application theory explains another aspect of similarity of imagining and believing mental states. According to the theory of John Urmson (1967) and Lloyd Humberstone (1992) imagining that $\mathrm{p}$ is like believing that $\mathrm{p}$, except it doesn't involve applying a norm of truth to one's representation that p. In other words one ought to believe what is true but one does not have to imagine what is true. In other words, representations where one does not apply the norm of truth remain in the realm of imagination. Sinhababu argues that it is possible to apply a norm of truth to one's imaginative representations without turning them into beliefs (Sinhababu 2016, 120). He puts forth an example of someone being passionately in love with an object of his or her desire and 
feeling guilty about that. Uncontrollable fantasies must violate some kind of norm, in order to cause a feeling of being guilty, Sinhababu suggests.

In my opinion in this case we should rather talk of ethical norms, which can be fully compatible with imaginative representations, but it is not a truth norm which causes the feeling of guilt. A religious person saying that she can imagine God does not exist and feels guilty about it, is not a victim of true or false norm, but rather of her "religious consciousness". Nevertheless, my main concern about the mentioned theory points to the fact that, as Wittgenstein shows in his late notes, even beliefs are not ruled by norms or at least not all of them. His examples demonstrate that there are beliefs which do not have truth-false value. These cannot be regarded subject to doubting or applying the norm of truth because they are the most fundamental ones. In other words, the fact of applying norms to beliefs is also arguable.

To sum up, beliefs and imagination can be similar in some ways, but they are certainly not similar categories. Most importantly, beliefs do not produce any kind of knowledge, since they are the result of a process of acquiring knowledge. Confirming the difference between imagination and belief we thus confirm a chance for imagination to be an epistemic tool but also acknowledge that imagination has a plenty of different aspects which makes general evaluation even more difficult if not impossible.

\section{Can we Learn by Imagining?}

In the first chapter I have suggested that only the local type of imagining can be fruitful in terms of epistemic results. Since two extremes, an "extremely local" example of imagining myself sitting and an extremely global one imagining of world's non-existence, seem to be too simplistic, let's move on to explore particular examples within the category of local imagining.

As mentioned earlier by being "local" I mean maintaining "hinges" of a particular form of life and language game. After dismissing the possibility to use global imagining as a fully functional epistemic tool, only the local one, as a possible source of knowledge, remains. Local imagining can include mental simulation of our body movements, other people's behavior or any other situation, not breaking our hinges in its broad sense. So, is learning by local imagining possible?

As Greg Currie suggests in the beginning of his article, some pathways to learning pass through the imagination; some even start with it (Currie 2016 , 407). In order to say I can learn by imagining, it is necessary to specify what kind of epistemological result is to be achieved. We can take 
learning in its broad sense in this case. According to Currie, learning can include a wide variety of knowledge types: propositional and sentential knowledge, regarded by him as a subtype of propositional knowledge, or an epistemic move from one paradigm to another not resulting in any specific kind of knowledge. In some cases "knowing how" is just another form of knowing a proposition. However, other types of knowledge cannot be reduced to propositional knowledge, since it includes an experiential or practice aspect, like for example knowing how to ride a bike. Imagination is often said to lead to knowing how something is like, to an "acquaintance", in other words. According to Currie imagination can aid both to propositional knowledge and experiential acquisition, since it aids the "transition from less reasonable to more reasonable" belief. It is not so important, though, to focus on knowledge itself, says Currie, since there are cases "which constitute learning without constituting the acquisition of knowledge (Currie 2016, 408).

Although imagining can result in different kind of knowing, Currie suggests that imagining can be either reliable or not. It means that imagining either helps in knowledge acquistion or you just think it does. The effectively engaged imagining must then give you a true belief you can rely on. A research into so called "effective forecasting" is providing examples of unreliability of imagination in certain cases. For instance, people tend to expect that both they and their partners will be more upset by a being unfaithful in their relationship than they actually are; these people may imagine emotional response which suggests to them greater unhappiness than in the situation actually occurs. In one study of this phenomenon participants correctly predicted that they would be more distressed in the role of offender than in the role of victim, but incorrectly predicted that their partner would be more distressed as victim than as perpetrator, suggesting difficulties with imaginative projection into another's situation (Green et al. 2013). One of the reasons to overestimate emotional response is immune neglect which helps us to cope with negative emotions. Surprisingly or not we tend to overestimate our positive emotions too (Green et al. 2013).

On the other hand, in Currie's opinion even when our imagining is totally unreliable, it can still be useful in predicting others' choices driven by the same unreliability (Currie 2016, 411). Common experience gained earlier in our lives suggests imagination can help in predicting outcomes of causal development, though this type of predicting is limited to a certain number of cases. We can imagine and predict vase falling and breaking down by throwing a mere look on its location on the edge of the table. 
On the other hand, we cannot predict what time is it by imagining we are looking at watches.

We are also good at imagining and predicting our physical abilities involving bodily interventions. For example, I can estimate I can climb a mountain without actually having done so. How this might be done in such a way as to provide reliable information is not well understood, says Currie, but it could hardly be done at all if imagining myself moving would fail to respect the constraints on actual movement"(Currie 2016, 411). One plausible explanation according to him is that in some cases imagining uses the same casual pathways as belief does. It seems for example that imagining movements and moving activate the same part of cognitive system.

According to L. Parsons's conclusions (Parsons 1994), common brain systems are activated in both imagining moving hands and in actual hand moving. During the research „mental simulation time mimicked movement time for natural efficient movement from a posture midway between each of the hand's joint limits into many other postures". "Equal time was required for simulated and real movements into more common, comfortable postures; shorter but proportional time was required for simulated movement than real movement into less common postures that involved longer trajectories, coordinated activity at more joints, motion near extremes of joint limits, and uncomfortable kinesthetic sensations" (Parsons 1994). At the same time according to collective research lead by P. Dominey actual performance due to brain damage (Parkinson's disease in this case) are sometimes predictable from imagined performance (Dominey - Decety Brouselle, 1995).

Although a number of other researches conforming connection between imagining and performing movements can be found, Currie notes, that ,the correspondence between real and imagined actions is relatively fragile"(Currie 2016, 412). An example of this fragility is shown by behavioral and brain research aimed at timing of mentally represented actions. For example, while actual and imagined walks over a certain distance took similar times for subjects of Decety's research, the correspondence was significantly weaker for subjects asked to carry heavy packs during their walking (Decety et al. 1989). So, the main lesson learned, there is no general answer to the general question "Can we learn through local imagining how we would feel or act in situations we have not encountered?" The general question should be replaced with a number of more specific and more wittgensteinian questions like: „Can we learn through imagination about the valance (duration, intensity) of our feelings in a particular type of situation?" And as Currie and other researchers mentioned conclude, 
only to some of these questions, the answer will be yes. Local imagining can be a useful epistemic tool in some cases, although its result can be interfered by a great number of factors or dispositions.

\section{References}

CURRIE, G. (2016): Imagination and learning. In (ed.) A. Kind: The Routledge Handbook of Philsophy of Imagiantion. London: Routledge, 407-420.

AUSTIN, J. (1979): Philosophical papers. Oxford: Oxford University Press.

DECETY, J. - JEANNEROD, M. - PREBLANC, C. (1989): The Timing of Mentally Represented Actions. In: Behavioral and Brain Research (34), 35-42.

DOMINEY, P.- DECETY, J. - BROUSELLE, E. (n.d.): Motor Imagery of a Lateralized Sequential Task is Asymmetrically Slowed in Hemi-Parkinson's Patients. In: Neuropsychologia, (33), 727-741.

GREEN, J.- DAVIS, J. - LUCHIES, L. - COY, A.E. - REID, C. (2013): Victims versus Perpetrators: Affective and Empathic Forecasting Regarding Transgressions in Romantic Relationships. In: Journal of Experimental Social Psychology, (49), 329-333.

HUMEBRSTONE, I. (1992): Direction of Fit. In: Mind, 101 (401), 59-83.

KIND, A. (2001): Putting the Image Back in Imagination. In: Philosophy and Phenomenological Research, 62 (1), 85-109.

MALCOLM, N. (1949): Defending Common Sense. In: The Philosophical Review, 58 (3), 201-220.

MALCOLM, N. (1977): Moore and Wittgenstein on the Sense of „I Know“. In: N. Malcolm: Thought and Knowledge: Essays. London: Cornell University Press, 170-198.

NAGEL, T. (1974): What Is It Like to Be a Bat?. In: The Philosophical Review, 83 (4), 435-450.

NICHOLS, S. - STICH, S. (2000): A Cognitive Theory of Pretense. In: Cognition, (74), 115-147.

PARSONS, L. (1994): Temporal and Kinematic Properties of Motor Behaviour Reflected in Mentally Simulated Action. In: Journal of Experimental Psychology: Human Perception and Performance, (20), 709-730.

PRITCHARD, D. (2015): Epistemic Angst: Radical Skepticism and the Groundlessness of Our Believing. Princeton: Princeton University Press.

RYLE, G. (1965): The Concept of Mind. New York: Barnes \& Noble.

SINHABABU, N. (2016): Imagination and Belief. In: A. Kind(ed.): The Routledge Handbook of Philosophy of Imagination. London: Routledge, 111-124.

SORENSEN, P. (2016): Thought Experiment and Imagination. In: A. Kind(ed.): The Routledge Handbook of Philosophy of Imagination. London: Routledge, 420-437.

URMSON, J. (1967): Memory and Imagination. In: Mind, 76 (301), 83-91.

WITTGENSTEIN, L. (1969): On Certainty. Oxford: Blackwell. 
Mgr. Kristina Veinbender

Katedra obecné antropologie

Fakulta humanitních studií

Univerzita Karlova

Pátkova 2137/5

18200 Praha 8 - Libeň

kristina.veinbender@seznam.cz 